\title{
ATUALIZAÇÕES SOBRE INTERNACIONALIZAÇÃO DA EDUCAÇÃO DE SURDOS
}

\author{
Indiamaris PEREIRA ${ }^{i}$ \\ Paulo Roberto SEHNEMii
}

\begin{abstract}
RESUMO
Fundamentado no referencial teórico da Internacionalização Abrangente e por meio de uma revisão sistemática, objetivou-se descrever as tendências na produção científica brasileira sobre internacionalização na educação de surdos para responder à problemática: quais são as tendências na produção científica brasileira sobre internacionalização na Educação de Surdos? Aferiu-se que a internacionalização é um tema que vem sendo explorado na atualidade das pesquisas sobre educação de surdos e evidenciou-se o crescente interesse da comunidade acadêmica. Conclui-se que a internacionalização na educação de surdos é uma lacuna a ser exploradas em pesquisas futuras.
\end{abstract}

PALAVRAS-CHAVE: Internacionalização da Educação; Educação de Surdos; Bilinguismo.

\section{UPDATES ON INTERNATIONALIZATION OF DEAF EDUCATION}

\begin{abstract}
Based on the theoretical framework of Comprehensive Internationalization and through a systematic review, this research aimed to describe the trends in Brazilian scientific production on internationalization in Deaf Education to answer the question: what are the trends in Brazilian scientific production on internationalization in deaf education? It was found that internationalization is a topic that has been explored in the current research on education for the deaf, as well as the growing interest of the academic community. It is concluded that the internationalization in the education of the deaf is a gap to be explored in future researches.
\end{abstract}

KEYWORDS: Internationalization of Education; Deaf Education; Deafnesss.

i Mestrado em Educação. Docente no Instituto Federal de Educação, Ciência e Tecnologia de Santa Catarina. Email: indiamaris@gmail.com - ORCID iD: http://orcid.org/0000-0001-5145-9522.

ii Doutorado em Educação pela Universidade do Vale do Itajaí (UNIVALI) com estágio sanduíche na Universidade de Salamanca, Espanha. Diretor Executivo da LUPA Assessoria e Treinamento e Presidente da Associação de Pesquisa e Extensão em Educação de Joinville (APEEJ). E-mail: paulo@ webespanhol.com.br - ORCID iD: https://orcid.org/0000-0001-8750-5367. 


\title{
ACTUALIZACIONES SOBRE LA INTERNACIONALIZACIÓN DE LA EDUCACIÓN PARA SORDOS
}

\begin{abstract}
RESUMEN
Con base en el marco teórico de la Internacionalización Integral y mediante una revisión sistemática, el objetivo fue describir las tendencias de la producción científica brasileña sobre la internacionalización en la educación de sordos para responder al problema: ¿cuáles son las tendencias de la producción científica brasileña sobre la internacionalización en la educación de sordos? Se constató que la internacionalización es un tema que se ha explorado en las investigaciones actuales sobre educación para sordos, así como el creciente interés de la comunidad académica. Se concluye que la internacionalización en la educación de los sordos es una brecha a explorar en futuras investigaciones
\end{abstract}

PALABRAS CLAVE: Internacionalización de la educación; Educación para sordos; Sordera.

\section{INTRODUÇÃO}

As discussões que aqui tecemos emergem dos estudos de revisão de literatura (sistemáticas e narrativas) desenvolvidas no grupo de pesquisa Estudos Linguísticos e Internacionalização do Currículo, na Universidade do Vale do Itajaí (UNIVALI), durante dos anos de 2017 e 2018, no campus de Itajaí. Durante as investigações tecidas nesse espaço epistemológico, confirmamos que a internacionalização das Instituições de Ensino Superior (IES) é de fato um dos grandes elementos estratégicos para a construção dos saberes necessários para a formação dos acadêmicos dos diversos cursos no Ensino Superior (ES) na atualidade.

Em tempos de globalização, a internacionalização tornou-se um relevante fator de diferenciação para as nações do mundo. Atualmente, as IES do mundo todo têm investido cada vez mais esforços para ampliar suas relações transnacionais, como também se organizado em busca de tornarem-se internacionais.

Nessa busca desenfreada pela internacionalização, muitas IES investem, equivocadamente, em práticas consideradas tradicionais de internacionalização. Dentre as práticas tradicionais, os programas de mobilidade estudantil e/ou docente e a oferta de cursos em língua estrangeira representam algumas das principais atividades desenvolvidas na empreitada pela internacionalização.

No entanto, algumas complicações oriundas das práticas tradicionais de internacionalização têm despertado atenção e preocupação de pesquisadores do campo da 
internacionalização. Conforme apresentamos em trabalho anterior, a seletividade e o fracasso da mobilidade discente para a aprendizagem e para o desenvolvimento das competências interculturais, tanto dos sujeitos que não tem condições de participar dos programas de mobilidade física, tal qual dos sujeitos que têm acesso a essas atividades, são fatores que têm feito com que estudiosos do mundo todo se debrucem cada vez mais sobre novas formas de se pensar e se fazer os processos de internacionalização acontecerem no ES (PEREIRA; SEHNEM 2018).

Na esteira da preocupação com os desafios que emergem quando uma IES leva a sério a amplitude do que o processo de internacionalização representa para o projeto de sociedade que idealiza sobre os pilares da identidade universitária (ensino, pesquisa e extensão) manifestase a nossa inquietação quanto à inserção dos estudantes surdos nos projetos de internacionalização das IES; inquietude que consideramos expandida aos demais coletivos singulares que não parecem terem sido destacados como sujeitos da internacionalização.

Quando as IES não se ocupam de pensar em um processo de internacionalização que contemple toda a comunidade acadêmica, arriscam-se a repetir, com novas roupagens, a velha internacionalização elitista que tem sido tão criticada nos tempos atuais. Nessa perspectiva, emerge o conceito de Comprehensive Internationalization (CI), que vem sendo traduzido para a língua portuguesa como Internacionalização Abrangente ou Inclusiva (DE WIT, 2015).

A CI é fruto do reconhecimento das diversas realidades, dentre elas a da circulação global de ideias praticamente instantâneas pela Internet (HUDZIK; MCCARTHY, 2013; HUDZIK, 2010). O conceito de CI é uma extensão da definição de internacionalização proposta anteriormente ${ }^{1}$. A definição estendida para CI é:

A internacionalização abrangente é um compromisso, confirmado através da ação, para infundir perspectivas internacionais e comparativas ao longo das missões de ensino, pesquisa e serviço do ensino superior. Ele molda o ethos e os valores institucionais e atinge toda a empresa de ensino superior. É essencial que seja adotado pela liderança institucional, governança, professores, alunos e todas as unidades de serviço e suporte acadêmico. É um imperativo institucional, não apenas uma possibilidade desejável (HUDZIK, 2010, p. 2).

Pela definição acima redigida é perceptível que, quando empreendida com eficácia, a CI impacta na aprendizagem de todos os envolvidos no espaço acadêmico. A CI busca a infusão 
das dimensões locais, globais e internacionais no momento formal de sala de aula e em todo o campus (HUDZIK; MCCARTHY, 2013; HUDZIK, 2010).

Embora tenha sido defendido que caracterizar a internacionalização como abrangente, ou inclusiva, é uma redundância, visto que se não for abrangente não é internacionalização, e sim a velha educação internacional elitista e exclusivista, na atualidade, o termo passou a ser amplamente difundido diante dos inúmeros achados, no mundo todo, que denunciam os fracassos gerados pelas más condições e desentendimentos a respeito da internacionalização que tem deixado de fora maior parte da população estudantil.

Na esteira das práticas inclusivas de internacionalização, temos sustentado que a Libras, no ES, pode ser explorada como prática de internacionalização em casa na perspectiva da interculturalidade e para contribuir com a construção do currículo do ES pautado na valorização da diferença, no respeito ao próximo e na solidariedade. Também temos explicado que pensar nos aspectos internacionais e ignorar a diversidade linguística inerente ao próprio país certamente seria manter o colonialismo que buscamos combater.

Apesar da busca intensa que empreendemos, não resgatamos pesquisas de revisão de literatura com o objetivo de mapear os trabalhos acadêmicos sobre a internacionalização na educação de surdos publicadas no Brasil, por isso nos propomos a fazê-lo. Sendo essa a atual fronteira do conhecimento, referendamos a pertinência do presente estudo, que, para além dos seus objetivos técnicos de pesquisa, tem também a pretensão de contribuir com a comunidade científica compartilhando achados atualizados do campo da internacionalização na educação de surdos.

Os processos formativos voltados a assegurar a formação e o desenvolvimento dos sujeitos surdos serão compreendidos como educação de surdos. Por surdo, nesse estudo, nos referimos aos sujeitos que compartilham a experiência visual como principal forma de exploração do mundo. Pela perspectiva teórica de base culturalista, surdez é um tópico a ser aludido dentro de abordagens culturais e epistemológicas, não da audiologia. Dessa forma, é possível pensar a surdez de outros modos que não pela perspectiva apenas clínica (LOPES, 2017). Portanto, assim como demais pesquisadores atuais, não temos o objetivo de discutir a inclusão e seus efeitos na escolarização e constituição da comunidade surda brasileira, ou seja, reconhece-se a importância dessas discussões, então parte-se delas para a problematização da educação de surdos (LOPES; THOMA, 2013).

Indiamaris PEREIRA, Paulo Roberto SEHNEM Atualizações sobre internacionalização da educação de surdos 
No presente artigo, seguimos o modelo IMRAD ${ }^{2}$, a seguir apresentaremos o método, os resultados e as principais análises. Findamos com algumas considerações autorais, seção na qual nos colocamos a refletir acerca das contribuições e limitações do presente estudo e apresentamos algumas lacunas evidenciadas durante a pesquisa.

\section{MÉTODO}

Para elaborar o desenho metodológico, seguimos os procedimentos recomendados por pesquisadores que estudam o método de revisão sistemática no campo da Educação e das Ciências Sociais (FARIA, 2016; RAMOS; FARIA; FARIA, 2014). O quadro abaixo apresenta, de forma sucinta, os processos da presente pesquisa:

Quadro 1 - Desenho metodológico da pesquisa

\begin{tabular}{|l|l|}
\hline \multicolumn{2}{|c|}{ Desenho Metodológico } \\
\hline Problemática & $\begin{array}{l}\text { Quais são as tendências na produção científica brasileira sobre } \\
\text { internacionalização na educação de surdos? }\end{array}$ \\
\hline Equação & educa* AND surd* AND internacional* \\
\hline Equação coringa & {$[*]$} \\
\hline Âmbito & https://catalogodeteses.capes.gov.br/catalogo-teses/\#!/ \\
\hline Data da Extração & $\begin{array}{l}\text { Extração inicial em: 10/06/2017. } \\
\text { Extração atualizada em: 15/11/2019. }\end{array}$ \\
\hline Critérios de inclusão & $\begin{array}{l}\text { Estudos que discutam processos de internacionalização na educação } \\
\text { de surdos. } \\
\text { Pesquisas desenvolvidas em Programas de Pos Graduação } \\
\text { brasileiros para obtenção de títulos Stricto Sensu. } \\
\text { Estudos publicados de 1987 até 2018. }\end{array}$ \\
\hline $\begin{array}{l}\text { Critérios de validade } \\
\text { metodológica }\end{array}$ & $\begin{array}{l}\text { Registro de cada etapa realizado por dois pesquisadores. } \\
\text { Replicação do processo de análise por dois pesquisadores. } \\
\text { Acompanhamento do processo por pesquisador externo. } \\
\text { Automatização do processo de extração. } \\
\text { Transparência dos dados em: }\end{array}$ \\
\hline Tratamento dos dados & Disponibilização dos dados brutos e análise descritiva. \\
\hline
\end{tabular}

Fonte: Os autores. 


\section{RESULTADOS}

Foram recuperadas trinta e nove pesquisas pela string de busca. Após leitura e aplicação dos critérios, onze estudos foram apurados como interessantes a essa investigação. O quadro a seguir apresenta quais:

Quadro 2 - Matriz de Síntese das pesquisas selecionados para o estudo

\begin{tabular}{|c|c|c|c|}
\hline Título & Autor & Defesa & Grau \\
\hline $\begin{array}{l}\text { ESTUDO DA AUTOADVOCACIA E } \\
\text { EMPODERAMENTO DE PESSOAS } \\
\text { COM DEFICIÊNCIA NO BRASIL E NO } \\
\text { CANADÁ }\end{array}$ & $\begin{array}{l}\text { TAISA } \\
\text { CALDAS } \\
\text { DANTAS }\end{array}$ & 2014-07-11 & Doutorado \\
\hline $\begin{array}{l}\text { LIBRAS E A DIVULGAÇÃO DOS } \\
\text { CONCEITOS CIENTÍFICOS SOBRE } \\
\text { CIÊNCIAS E BIOTECNOLOGIA: } \\
\text { INTEGRAÇÃO INTERNACIONAL DE } \\
\text { UM DICIONÁRIO CIENTÍFICO } \\
\text { ONLINE }\end{array}$ & $\begin{array}{l}\text { RUTH MARIA } \\
\text { MARIANI } \\
\text { BRAZ }\end{array}$ & 2014-07-31 & Doutorado \\
\hline $\begin{array}{l}\text { DA INCLUSÃO À CIDADANIA: UM } \\
\text { ESTUDO SOBRE O GRUPO DE } \\
\text { ESTUDOS SURDOS DA UCPEL }\end{array}$ & $\begin{array}{l}\text { BRENDA } \\
\text { TEIXEIRA DE } \\
\text { OLIVEIRA } \\
\text { SEQUEIRA } \\
\end{array}$ & 2015-10-30 & Mestrado \\
\hline $\begin{array}{l}\text { ADMIRÁ VEL MUNDO NOVO: A } \\
\text { CIÊNCIA E O SURDO }\end{array}$ & $\begin{array}{l}\text { JULIA } \\
\text { BARRAL } \\
\text { DODD } \\
\text { RUMJANEK }\end{array}$ & 2016-01-08 & Doutorado \\
\hline $\begin{array}{l}\text { EDUCAÇÃO BILÍNGUE DE FILHOS } \\
\text { OUVINTES DE PAIS SURDOS } \\
\text { (CODAs) COM O OLHAR DE PAIS } \\
\text { SURDOS }\end{array}$ & $\begin{array}{l}\text { RICARDO } \\
\text { ERNANI } \\
\text { SANDER }\end{array}$ & 2016-04-15 & Mestrado \\
\hline $\begin{array}{l}\text { A ESCOLARIZAÇÃO DE SURDOS E O } \\
\text { CONGRESSO DE MILÃO: ECLOSÃO } \\
\text { DA NORMALIZAÇÃO PARA } \\
\text { ORALIDADE. }\end{array}$ & $\begin{array}{l}\text { CLARISSA } \\
\text { FERNANDES } \\
\text { DAS DORES }\end{array}$ & $2017-05-15$ & Mestrado \\
\hline $\begin{array}{l}\text { A EDUCAÇÃO DE SURDOS PELOS } \\
\text { ESTÁGIOS DO PROCESSO DE } \\
\text { INTERNACIONALIZAÇÃO DO } \\
\text { CURRÍCULO }\end{array}$ & $\begin{array}{l}\text { VALKIRIA DE } \\
\text { NOVAIS } \\
\text { SANTIAGO }\end{array}$ & 2017-07-31 & Mestrado \\
\hline $\begin{array}{l}\text { INCLUSÃO DE ALUNOS SURDOS EM } \\
\text { CASTILLA-LA MANCHA (ESPANHA) }\end{array}$ & $\begin{array}{l}\text { DAIANE } \\
\text { NATALIA } \\
\text { SCHIAVON }\end{array}$ & $2017-08-24$ & Doutorado \\
\hline $\begin{array}{l}\text { PROJETO DE SOFTWARE PARA } \\
\text { INTERNACIONALIZAÇÃO EM } \\
\text { LÍNGUAS DE SINAIS }\end{array}$ & $\begin{array}{l}\text { PAULO } \\
\text { MARCOS } \\
\text { SOARES } \\
\text { RODRIGUES }\end{array}$ & 2017-08-30 & Mestrado \\
\hline RECONHECIMENTO DE LÍNGUAS & ALINE LUCIA & $2018-05-11$ & Mestrado \\
\hline
\end{tabular}




\begin{tabular}{|l|l|l|l|}
\hline DE SINAIS E EDUCAÇÃO DE & BAGGIO & & \\
SURDOS NO BRASIL E NA SUÉCIA & MONTES & & \\
\hline O ESTADO DO CONHECIMENTO & EDNA & & \\
SOBRE A EDUCAÇÃO DE SURDOS: O & MISSENO & $2018-08-24$ & Doutorado \\
DISCURSO EDUCACIONAL & PIRES & & \\
BRASILEIRO E O INTERNACIONAL. & & & \\
\hline
\end{tabular}

Fonte: Os autores.

\section{ANÁLISE}

O total de estudos que se debruçaram sobre a referida temática pode ser considerado escasso. Do ano de 1987, ano em que, segundo registro da Capes, foi defendido, no Brasil, o primeiro trabalho acadêmico sobre a temática educação de surdos, até o ano de 2019, ano em que se finaliza a extração de dados e se inicia a escrita final da presente pesquisa, estão catalogados 1147546 estudos, dentre os quais 192630 podem ser encontrados pela string [educa*], 2202 trabalhos acadêmicos [educa* AND surd]. Ao restringirmos a string de busca para [educa* AND surd* AND internacional*] encontramos o total de 39 pesquisas, que, como já citamos, após extraídas e analisadas resultaram em um corpus de apenas 11 estudos.

Os estudos apresentam pouca discrepância em relação ao grau acadêmico a que se referem. O gráfico a seguir explicita tal afirmativa:

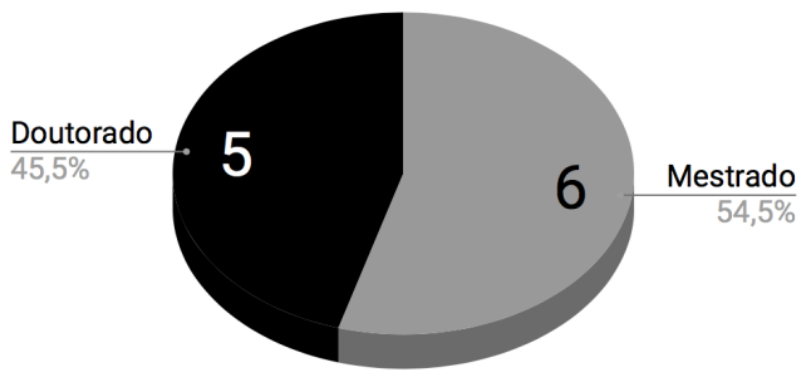

Gráfico 1 - Modalidades Fonte: Dados da pesquisa.

A análise das modalidades constitui indício para avaliar a maturidade e o aprofundamento dos estudos em um dado campo. No geral, os trabalhos acadêmicos Stricto 
Sensu, dissertações e teses, se diferenciam pelo ineditismo, pois as teses, que devem apresentar defesas inéditas oriundas de profunda investigação, representam um avanço para os estudos do campo em questão (DRUMMOND, 2003). O equilíbrio entre a quantidade de teses pode ser interpretado como um dado animador, visto que essas podem representar continuidade dos estudos e são pesquisas elaboradas por pesquisadores experientes.

A próxima análise tem por objetivo verificar as tendências na distribuição temporal desses estudos. Conforme o gráfico a seguir, podemos aferir que o campo da internacionalização na educação de estudos é um objeto de investigação novo, já que os registros iniciais datam de 2014.

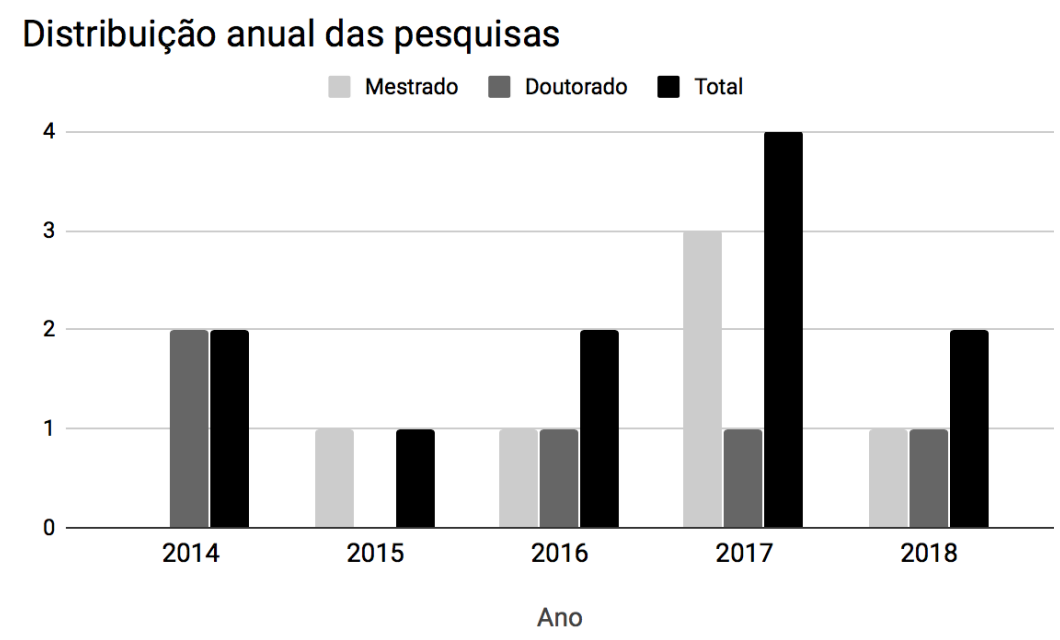

Gráfico 2 - Distribuição Anual Fonte: Dados da pesquisa.

É possível constatar que os estudos têm se intensificado nos últimos dois anos. $\mathrm{O}$ aumento das publicações, que dobrou em tal período, é um indicativo de uma nova realidade no campo das pesquisas sobre educação de surdos no Brasil, tendo como inserção problemáticas que discutem internacionalização. Tal fato pode ser dado pela temática da internacionalização ter evoluído acima das expectativas; que em termos de investimentos ultrapassou valores de aproximadamente 100 milhões de reais em 2010 para 900 milhões de reais em 2012 (BRASIL, 2010).

Conforme é demonstrado no quadro a seguir, dentre as IES em que se efetuou a defesa de tais pesquisas, as instituições públicas se destacam: 
Quadro 3 - Instituições das pesquisas

\begin{tabular}{|c|}
\hline UNIVERSIDADE FEDERAL DA PARAÍBA/JOÃO PESSOA \\
\hline UNIVERSIDADE FEDERAL FLUMINENSE \\
\hline UNIVERSIDADE CATÓLICA DE PELOTAS \\
\hline UNIVERSIDADE FEDERAL DO RIO DE JANEIRO \\
\hline UNIVERSIDADE ESTADUAL DE MARINGÁ \\
\hline UNIVERSIDADE FEDERAL DE OURO PRETO \\
\hline UNIVERSIDADE DO VALE DO ITAJAÍ \\
\hline $\begin{array}{l}\text { UNIVERSIDADE ESTADUAL PAULISTA JÚLIO DE MESQUITA FILHO } \\
\text { (ARARAQUARA) }\end{array}$ \\
\hline UNIVERSIDADE FEDERAL DE GOIÁS \\
\hline UNIVERSIDADE FEDERAL DE SÃO CARLOS \\
\hline PONTIFÍCIA UNIVERSIDADE CATÓLICA DE GOIÁS \\
\hline
\end{tabular}

Fonte: Dados da pesquisa.

Tal achado reforça a prerrogativa de que as IES públicas são instituições que alavancam o desenvolvimento científico do país. Após a identificação das instituições foi possível averiguar os estados e, consequentemente, as regiões em que as IES se encontravam.

\section{TOTAL DE TRABALHOS POR ESTADOS}

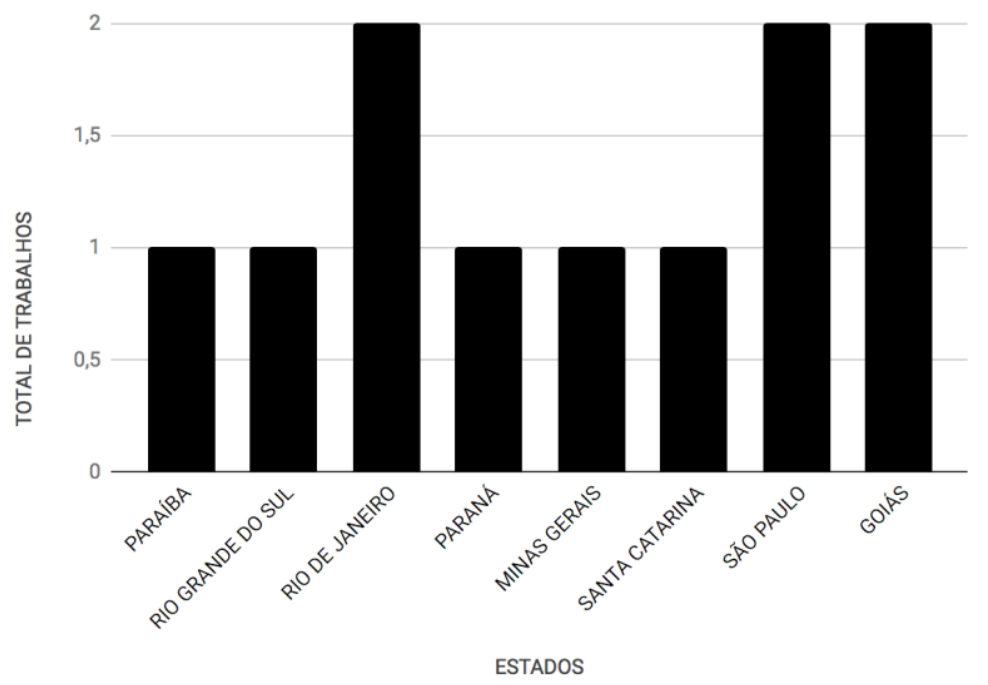

Gráfico 3 - Estados

Fonte: Dados da pesquisa. 


\section{TOTAL DE TRABALHOS POR REGIÃO}

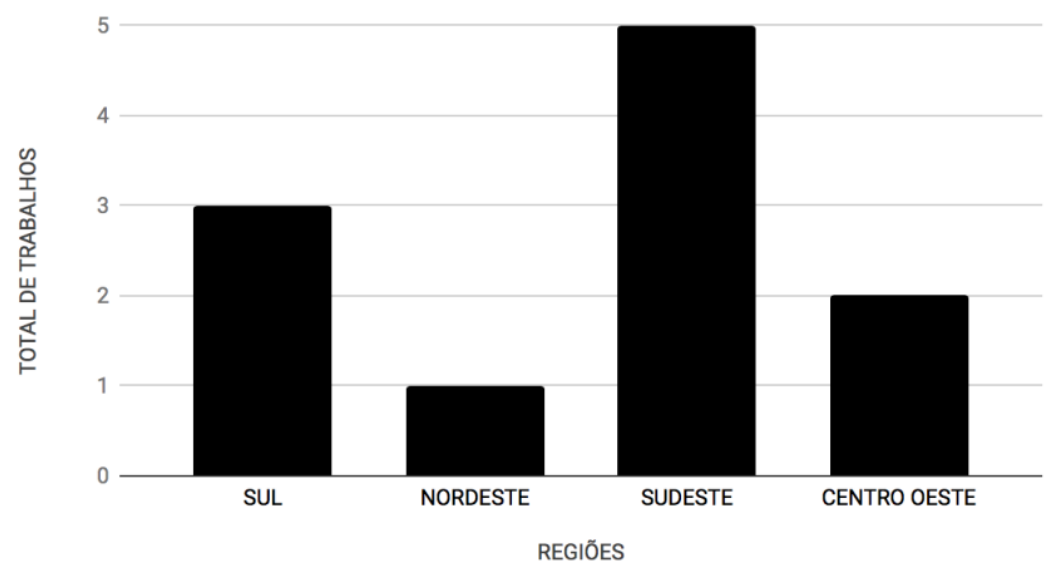

Gráfico 4 - Regiões

Fonte: Dados da pesquisa.

Além de ser uma das características que delineiam o perfil das instituições e de revelar em quais lugares há maior quantidade de pesquisas, a compreensão desse dado também possibilita pensar sobre a contribuição dessas regiões na produção e sistematização de novos conhecimentos.

Os dados obtidos podem ser relacionados com as assimetrias na distribuição regional dos PPG no Brasil. Segundo a Capes, a região Sudeste é a que mais possui PPG no Brasil; a região Sul fica em segundo lugar, seguida pela região Nordeste. As assimetrias existentes no sistema de pós-graduação brasileiro têm sido tema de discussão nos planos nacionais que discutem educação.

Face à existência de um quadro de assimetrias, o Plano Nacional de Programas de Pós Graduação revela preocupações com tal fenômeno. No documento, o assunto é considerado importante para o desenvolvimento do país; o combate às assimetrias é tomado como uma temática cuja complexidade irá exigir a ação sinérgica de vários órgãos do governo (BRASIL, 2010).

Cabe também lembrar que o estado de Santa Catarina sedia o único Campus Bilíngue de Educação Científica e Tecnológica da América Latina e foi pioneiro na implantação do curso de Letras Libras (licenciatura e bacharelado). Já no Rio de Janeiro reside o Instituto Nacional de Educação de Surdos (INES) que é uma importante instituição na história da educação dos surdos no Brasil (WITCHS; LOPES; COELHO, 2019). 


\subsection{Algumas temáticas em discussão no Brasil}

A imagem a seguir apresenta as temáticas exploradas nas pesquisas recuperadas nesse estudo e o entrecruzamento de temas:

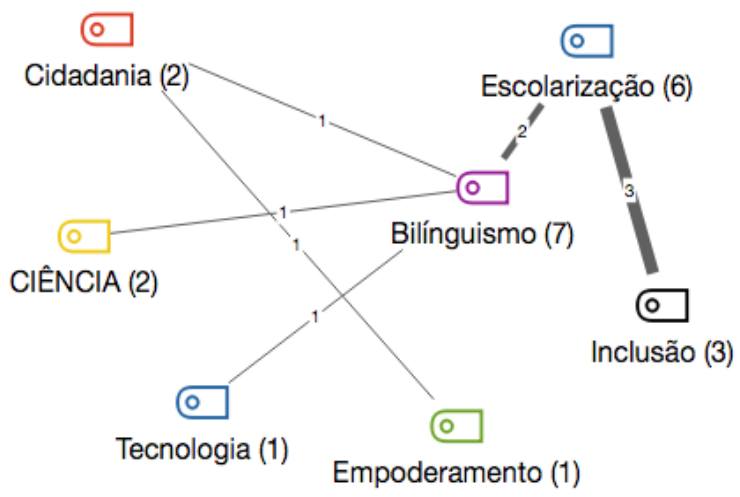

Figura 1 - Temáticas Fonte: Dados da pesquisa.

Os resultados indicam que o bilinguismo é o nó que conecta as temáticas exploradas. As questões linguísticas também são destacadas nos estudos que discutem a internacionalização em outros campos. No entanto, cabe lembrar que o bilinguismo vivido pela comunidade surda ultrapassa o conceito de fluência em duas línguas, uma vez que os membros dessa comunidade usam a língua de sinais e a língua oral oficial do país, ou seja, trata-se de um bilinguismo também bimodal. Apesar de vários surdos serem fluentes em mais de uma língua de sinais, não há sociedades conhecidas nas quais todos sejam surdos e, consequentemente, não existe uma situação de monolinguismo territorial ou bilinguismo apenas em uma modalidade nessa comunidade (ANN, 2001; GROSJEAN, 2008; WOLL; MACSWEENEY, 2016). A seguir detalhamos como as temáticas foram exploradas em cada uma dessas pesquisas.

A tese intitulada "Estudo da autoadvocacia e empoderamento de pessoas com deficiência no Brasil e no Canadá" teve como foco a realidade político-global e coletivoindividual da educação de pessoas com deficiência no Brasil e no Canadá. Tal estudo cita que 
o movimento internacional das pessoas com deficiência vem dando destaque à necessidade urgente de garantia dos direitos humanos para o exercício da cidadania e participação social dessas pessoas (DANTAS, 2014).

Já a tese "LIBRAS e a divulgação dos conceitos científicos sobre ciências e biotecnologia: integração internacional de um dicionário científico online", explica que a ausência de termos priva o aluno surdo do acesso à informação, compromete seu conhecimento para ascender ao ES e o priva do direito à cidadania plena garantida por lei (BRAZ, 2014).

No ano de 2015 se deu a defesa do trabalho de mestrado "Da inclusão à Cidadania: um estudo sobre o grupo de estudos surdos da UCPel" na Universidade Católica de Pelotas. A referida investigação também retrata as contribuições dos documentos e eventos internacionais, como a Convenção Internacional Sobre o Direito das Pessoas com Deficiência, para a mudança do olhar voltado às pessoas com deficiência nos diversos âmbitos, dentre eles o educacional, mas não aborda as questões alocadas no âmbito do processo de internacionalização do currículo voltado à formação dos estudantes surdos.

O estudo "Admirável Mundo Novo: A Ciência e o Surdo" afirmou que existe uma limitação dos termos científicos existentes em Libras, que tal fato cria uma barreira linguística para a comunicação e compreensão da ciência. O estudo objetivou "criar uma aproximação com o mundo científico. Para tal torna-se necessário um glossário científico em Libras" (RUMJANEK, 2016, p. 410). Como resultado, a pesquisa apresenta a expansão do conhecimento e da acessibilidade, para os surdos, para outras áreas culturais (RUMJANEK, 2016).

A dissertação "Educação bilíngue de filhos ouvintes de pais surdos (codas) com o olhar de pais surdos", desenvolvida também na já citada Universidade Estadual de Maringá, promoveu reflexões acerca de processos comunicativos e aspectos da aprendizagem e desenvolvimento dos filhos ouvintes de pais surdos, em contexto familiar de educação bilíngue. Esse trabalho apresentou a organização internacional dos filhos ouvintes de pais surdos, discutiu a condição bilíngue desses sujeitos, tal qual o crescimento e desenvolvimento de crianças ouvintes filhas de pais surdos em um contexto bilíngue e bimodal, que transitam entre língua, modalidade e culturas diferentes. A autora apresenta pesquisas desenvolvidas em países como Portugal, Estados Unidos e Brasil e, assim como os demais trabalhos, também explorou a influência de eventos e documentos internacionais, como a Conferência Internacional do 
Trabalho em Genebra, de 1983, a Declaração Internacional de Montreal sobre Inclusão, de 2001, e a Convenção Internacional sobre os Direitos das Pessoas com Deficiência.

O estudo "A escolarização dos surdos e o Congresso de Milão: eclosão da normalização para oralidade" analisou práticas e procedimentos que estruturaram a educação de surdos com base na oralidade ao longo da história da educação de surdos no mundo e no Brasil, em especial a partir do século XIX. Tendo como objeto documentos do Congresso de Milão e de Paris, os achados indicam que, de uma maneira ou de outra, as estratégias e práticas propostas ainda repercutem significativamente nos dias de hoje.

A dissertação "A educação de Surdos pelos Estágios do Processo de Internacionalização do Currículo" teve por objetivo geral validar o processo de internacionalização do currículo na educação de surdos pelos estágios e componentes de revisão/reflexão e imaginação. Tal pesquisa também explora o impacto de documentos e eventos internacionais sobre a educação de surdos no Brasil, também não evidenciou a conexão entre os acontecimentos e o estado atual da educação de surdos. Os lócus explorados é uma escola inclusiva, ambiente escolar citado pelos estudiosos da área como inapropriado para o desenvolvimento educacional de estudantes surdos, os achados da pesquisadora reforçam tal prerrogativa (SANTIAGO, 2017).

O estudo "Inclusão de alunos surdos em Castilla la Mancha (Espanha): reflexões para o contexto brasileiro" objetivou investigar o sistema educativo espanhol (Castilla-La Mancha) no que diz respeito à sua organização e às práticas pedagógicas para crianças surdas que frequentam a educação infantil e primária, com vistas a oferecer possibilidades de reflexão para o contexto brasileiro. De acordo com a pesquisa, a educação de alunos surdos é um tema de importância multinacional, cujo caráter internacional possibilita uma perspectiva de aproximação e diálogo entre diferentes contextos. Os resultados indicaram que, no recorte espanhol, foram encontradas variadas modalidades comunicativas para o surdo, porém, há a predominância da aquisição da linguagem oral, a qual está associada à utilização dos sinais da Língua Espanhola de Sinais, bem como evidenciou debates divergentes sobre a educação de surdos e sobre as modalidades linguísticas utilizadas em sua escolarização (SCHIAVON, 2017).

A pesquisa "Projeto de Software para Internacionalização em Línguas de Sinais" buscou desenvolver um projeto de software que permitisse internacionalização em relação às diversas 
línguas de sinais existentes, para tanto foi elaborado uma aplicação web. Dentre as conclusões oferecidas, destaca-se que a criação de uma arquitetura voltada para a internacionalização para as línguas de sinais, o estudo demonstrou que é possível ter aplicações voltadas para línguas espaço-visuais, tendo as línguas orais como um ente auxiliar na compreensão do conteúdo por parte dos usuários surdos (RODRIGUES, 2017).

Em 2018 a investigação "Reconhecimento de línguas de sinais e educação de surdos no Brasil e na Suécia" investigou, na perspectiva comparada, os documentos que reconhecem as línguas de sinais no Brasil e na Suécia e analisou se os respectivos reconhecimentos contribuíram para o processo educacional dos surdos em ambos os países. Dentre as conclusões do estudo, ficou evidente que na Suécia o direito de aquisição e uso da língua sueca de sinais, como língua materna, está previsto na lei e o país contribui efetivamente na criação de condições reais para a sua aquisição pela comunidade surda, enquanto no Brasil, como o direito à aquisição não é previsto em lei, o reconhecimento da Libras não garantiu ao surdos o direito à aquisição da língua de sinais e, também, não promoveu a garantia de uma educação bilíngue (MONTES, 2018).

Também em 2018, a tese "O estado do conhecimento sobre a educação de surdos: o discurso educacional brasileiro e o internacional" visou a compreender as vertentes teóricas e metodológicas para a educação de surdos no século XXI, explicitando quais são as proposições nacionais e internacionais mais presentes no discurso para a educação de surdos no Brasil. A tese apresentada é de que:

O discurso educacional brasileiro para surdos no século XXI está pautado no bilinguismo, apresentando-se em três vertentes: político, cultural e linguístico, sobretudo na vertente linguística que aparece como destaque para o reconhecimento do uso da língua de sinais na proposta atual para a educação de surdos (PIRES, 2018, p 14).

Dentre os achados, a pesquisa afirma que em todos os trabalhos analisados observou-se unanimidade quanto à ideia do bilinguismo na educação de surdos. Destaca que sobre a vertente linguística, presente no pensamento educacional brasileiro, a maioria dos trabalhos utilizaram a teorização de Vygotsky, consagrando-o, dessa forma, como autor clássico que norteia o discurso educacional brasileiro, pois os pesquisadores apropriaram-se dos estudos teóricos do autor russo, na vertente linguística, como argumento para a utilização da língua de sinais na educação de surdos (PIRES, 2018). 


\section{CONCLUSÃO}

O equilíbrio entre a quantidade de teses e dissertações pode ser interpretado como um indicador de continuidade dos estudos, enquanto a análise da cronologia pode significar o surgimento de novas questões de pesquisa, no âmbito da educação de surdos, relacionadas com a internacionalização, pois o o aumento das publicações é um indicativo de uma nova realidade. Interpretamos que a evolução da temática internacionalização acima das expectativas, inclusive em termos financeiros, é um fator que pode ter impulsionado essas pesquisas para a área da internacionalização.

Verificamos que a maior parte das IES em que esses estudos foram publicados são públicas e as regiões que se destacaram com maior número de publicações foram as que sediam importantes espaços formais de discussão da educação de surdos (INES e Campus Palhoça Bilíngue do IFSC). Tal dado ressalta a importância dessas instituições, públicas, na produção e atualização do conhecimento científico no Brasil.

A noção de bilinguismo foi percebida como o nó que conectou as temáticas estudadas pelas pesquisas, no entanto apenas um estudo encontrado se voltou a discutir diretamente o processo de internacionalização na educação de surdos, os demais apenas tangenciaram a temática. $\mathrm{O}$ bilinguismo tratado nessas pesquisas se caracteriza como multimodal, por se tratar da fluência em uma língua visual espacial e em outra oral.

No geral, podemos afirmar que as pesquisas que aprofundam, no Brasil, satisfatoriamente a problemática sobre a qual nos debruçamos não foram descobertas pela revisão e as que a puderam ser associadas são poucas, considerando que quando objetivamos tais produções como poucas tomamos como base uma concepção formada para além do senso comum, ou seja, buscamos uma base de comparação, longe de nos referimos às 1083988 retornadas pela busca coringa $[*]$.

Com base no exposto, consideramos evidente o afastamento entre os estudos que abordam educação de surdos e os estudos que abordam internacionalização. Diante tal fato se torna notória a lacuna a ser preenchida em âmbito nacional. Recomendamos que as discussões sobre mobilidade física internacional para estudantes surdos sejam abordadas e aprofundadas; 
indicamos que o contato internacional entre surdos seja objeto de pesquisa tanto quanto o é entre estudantes ouvintes.

\section{REFERÊNCIAS}

ANN, Jean. Bilingualism and language contact. In: LUCAS, Ceil (Org.). The

Sociolinguistics of Sign Languages. Washington: Cambridge University Press, 2001. p. 3360. Disponível em: https://doi.org/10.1017/CBO9780511612824.005. Acesso em: 5 out. 2020.

BRASIL. Ministério da Educação. Coordenação de Aperfeiçoamento de Pessoal de Nível Superior. Plano Nacional de Pos Graduação - PNPG 2011-2020. Brasília, DF: CAPES, 2010.

BRAZ, Ruth Maria Mariani. LIBRAS e a divulgação dos conceitos científicos sobre ciências e biotecnologia: integração internacional de um dicionário científico online. 2014. Tese (Doutorado em Ciências e Biotecnologia Instituição de Ensino) - Universidade Federal Fluminense, Niterói, 2014.

DANTAS, Taísa Caldas. Estudo da autoadvocacia e empoderamento de pessoas com deficiência no Brasil e no Canadá. 2014. Tese (Doutorado em Educação) - Universidade Federal da Paraíba, João Pessoa, 2014.

DE WIT, Hans. Recent Trends and Issues in International Student Mobility. International Higher Education, n. 59, 25 mar. 2015. Disponível em:

https://ejournals.bc.edu/index.php/ihe/article/view/8481. Acesso em: 5 out. 2020.

DORES, Clarissa Fernandes das. A escolarização de surdos e o congresso de milão: Eclosão da normalização para oralidade. 2017. Dissertação (Mestrado em Educação) Universidade Federal de Ouro Preto, Mariana, 2017.

DRUMMOND, José Augusto. Anotações de um integrante de bancas examinadoras: teses e dissertações defendidas recentemente na área de Ciências Ambientais. Ambiente \& Sociedade, v. 5, n. 2, p. 191-214, 2003. Disponível em: http://www.scielo.br/scielo.php?script=sci_arttext\&pid=S1414753X2003000200011\&lng=pt\&tlng=pt. Acesso em: 5 out. 2020.

FARIA, Paulo Mario. Revisão Sistemática da Literatura: Contributo para um Novo Paradigma Investigativo. Metodologia e Procedimentos na área das Ciências da Educação Aplicação prática aos temas desenvolvimento profissional docente e inovação educativa com tecnologias digitais. Portugal, Santo Tirso: Whitebooks, 2016. 
GROSJEAN, François. The bilingual and the bicultural person in the hearing and in the deaf world. Sign language studies, v. 77, 1992, p. 307-320. Disponível em:

https://www.francoisgrosjean.ch/sign_deaf/5.\%20Grosjean.pdf. Acesso em: 25 jul. 2021.

GROSJEAN, François. Individual Bilingualism. In: ASHER, Ronald (Org.). The encyclopedia of language and linguistics. Oxford: Oxford Pergamon Press, 1994. p. 16561660.

HUDZIK, Jonh.; Comprehensive internationalization: From concept to action. Washington: NAFSA e-Publications, 2010.

HUDZIK, Jonh.; MCCARTHY, J. Leading comprehensive internationalization: strategy and tactics for action. Washington: NAFSA e-Publications, 2013.

LOPES, Maura Corcini. Professores Interlocutores e Educação de Surdos: a Inclusão na Rede Estadual Paulista. Revista Brasileira de Educação Especial, [s. 1.], 2017. Disponível em: http://www.scielo.br/scielo.php?pid=S1413-65382017000400563\&script=sci_arttext. Acesso em: 25 jul. 2021.

LOPES, Maura Corcini; THOMA, Adriana da Silva. Subjectivation, normalisation et constitution de l'éthos sourd: politiques publiques et paradoxes contemporains. La Nouvelle Revue de l'Adaptation et de la Scolarisation, v. 1, p. 105-116, 2013. Disponível em: https://www.scielo.br/scielo.php?script=sci_nlinks\&pid=S21756236201600030075500037\&lng=en. Acesso em: 5 out. 2020.

LOPES, Maura Corcini; VEIGA-NETO, Alfredo. Acima de tudo, que a escola nos ensine. Em defesa da escola de surdos. ETD - Educação Temática Digital, v. 19, n. 4, p. 691, 6 out. 2017. Disponível em: https://periodicos.sbu.unicamp.br/ojs/index.php/etd/article/view/8648637. Acesso em: 5 out. 2020.

MONTES, Aline Lucia Baggio. Reconhecimento de línguas de sinais e educação de surdos no Brasil e na Suécia. 2018. Dissertação (Mestrado em Educação Especial) - Universidade Federal de São Carlos, São Carlos, 2018.

PEREIRA, Indiamaris.; SEHNEM, Paulo. Roberto. O potencial da disciplina de libras como estratégia de internacionalização do ensino superior. Interletras, Dourados, v. 8, p. 01-14, 2018. Disponível em:

https://www.unigran.br/interletras/ed_anteriores/n28/conteudo/artigos/10.pdf. Acesso em: 20 ago. 2020.

PIRES, Edna Misseno. O estado do conhecimento sobre a educação de surdos: o discurso educacional brasileiro e o internacional. 2018. Tese (Doutorado em Educação) - Pontifícia Universidade Católica de Goiás, Goiânia, 2018. 
RAMOS, Altina.; FARIA, Paulo; FARIA, Ádila. Revisão sistemática de literatura: contributo para a inovação na investigação em Ciências da Educação. Revista Diálogo Educacional, v. 14, n. 41, p. 17, 12 jul. 2014. Disponível em:

https://periodicos.pucpr.br/index.php/dialogoeducacional/article/view/2269. Acesso em: 5 out. 2020.

RODRIGUES, Paulo Marcos Soares. Projeto de Software para Internacionalização em Línguas de Sinais. 2017. Dissertação (Mestrado em Ciência da Computação) - Universidade Federal de Goiás, Goiânia, 2017.

RUMJANEK, Júlia Barral Dodd. Admirável Mundo Novo: A Ciência e o Surdo. 2016. Tese (Doutorado em Química Biológica) - Universidade Federal do Rio de Janeiro, Rio de Janeiro, 2016.

SANDER, Ricardo Ernani. Educação bilíngue de filhos ouvintes de pais surdos (codas) com o olhar de pais surdos. 2016. Dissertação (Mestrado em Educação) - Universidade Estadual de Maringá, Maringá, 2016.

SANTIAGO, Valkiria Novais. A educação de surdos pelos estágios do processo de internacionalização do currículo. 2017. Dissertação (Mestrado em Educação) Universidade do Vale do Itajaí, Itajaí, 2017.

SEQUEIRA, Brenda Teixeira Oliveira Da inclusão à cidadania: um estudo sobre o grupo de estudos surdos da UCPel. 2015. Dissertação (Mestrado em Política Social) - Universidade Católica de Pelotas, Pelotas, 2015.

SCHIAVON, Daiane Natália. Inclusão de alunos surdos em Castilla-la Mancha (Espanha): reflexões para o contexto brasileiro. 2017. Tese (Doutorado em Educação Escolar) - Universidade Estadual Paulista Júlio de Mesquita Filho, Araraquara, 2017.

WITCHS, Paulo Henrique; LOPES, Maura Corcini; COELHO, Orquídea. Formas possíveis de ser nas políticas linguísticas de educação de surdos em Portugal. Educação \& Sociedade, v. 40, p.53, 2019. Disponível em: http://www.scielo.br/scielo.php?script=sci_arttext\&pid=S010173302019000100316\&tlng=pt. Acesso em: 5 out. 2020.

WOLL, Bencie; MACSWEENEY, Mairéad. Let's not forget the role of deafness in sign/speech bilingualism. Bilingualism, language and cognition, v. 19, n. 2, 2016, p. 253 255. Disponível em: https://www.ncbi.nlm.nih.gov/pmc/articles/PMC4920218/. Acesso em 24 jul. 2021. 
Programa de Pós-Graduação em Educação: Currículo

\section{NOTAS:}

${ }^{1}$ Ver mais em: https://journals.sagepub.com/doi/10.1177/1028315303260832.

${ }^{2}$ Ver mais em: https://writingcenter.gmu.edu/guides/writing-an-imrad-report.

Recebido em: 20/12/2019

Aprovado em: 05/10/2020 